\title{
Efeito do Glyphosate sobre a Morfoanatomia das Folhas e do CAUle DE Commelina diffusa E C. benghalensis ${ }^{1}$
}

\author{
Effect of Glyphosate on the Morpho-Anatomy of Leaves and Stems of C. diffusa and \\ C. benghalensis
}

TUFFI SANTOS, L.D. ${ }^{2}$, MEIRA, R.M.S.A. ${ }^{3}$, SANTOS, I.C. ${ }^{4}$ e FERREIRA, F.A. ${ }^{5}$

\begin{abstract}
RESUMO - O objetivo deste trabalho foi avaliar o efeito do glyphosate nas estruturas anatômicas e morfológicas do caule e das folhas de duas espécies de Commelina, bem como investigar o envolvimento do amido de reserva na maior tolerância ao glyphosate de C. diffusa em relação a $C$. benghalensis. De 10 vasos cultivados de cada espécie, nove receberam $1.440 \mathrm{~g} \mathrm{ha}^{-1}$ de glyphosate e um serviu como testemunha. Fragmentos de caule e folhas foram coletados e fixados nos tempos de zero (antes da aplicação do glyphosate), 15, 30 e 50 dias após a aplicação (DAA). O laminário histológico foi obtido conforme metodologia usual, enfatizando-se a aplicação do reagente lugol para verificação de amido. Atribuíramse notas de 1 a 5, conforme a intensidade crescente da reação. $\mathrm{Na}$ folha, as células epidérmicas e os tecidos vasculares são pouco afetados; já o mesofilo é integralmente desorganizado, culminando com a morte das células. As injúrias são mais evidentes no caule e nas folhas de $C$. benghalensis. Morfologicamente, verificam-se regiões cloróticas e áreas necrosadas dispersas pela superfície foliar, culminando com a queda a partir do 15o DAA em C. benghalensis. Em C. diffusa, a abscisão foliar é mais tardia, apesar de as injúrias serem semelhantes. Ambas as espécies apresentaram maior quantidade de amido na região do nó que do entrenó. C. benghalensis tem poucos e pequenos grãos de amido, enquanto em C. difusaeles são grandes e numerosos. Em resposta à aplicação do glyphosate, houve variação na quantidade de grãos de amido no caule conforme o tempo após a aplicação. Assim, C. difusa terá sempre maiores possibilidades de se restabelecer após aplicação do glyphosate, por manter maior reserva de amido.
\end{abstract}

Palavras-chave: trapoeraba, tolerância, controle químico.

\begin{abstract}
The purpose of this work was to evaluate the effect of glyphosate in the anatomical and morphologic structures of leaves and stems of two species of Commelina, and to investigate the involvement of the starch reservation in larger tolerance to glyphosate of $\mathbf{C}$. diffusa in relation to $\mathbf{C}$. benghalensis. From 10 pots for each species, 9 were applied with $1440 \mathrm{~g} \mathrm{ha}$ of glyphosate and one was used as check. Fragments of stems and leaves were collected and fixed at time zero (before the application of glyphosate), 15, 30, and 50 days after the application (DAA). The histological slides were obtained according to the usual methodology, with emphasis to the application of the lugol reagent to check starch. Grades from 1 to 5 were given according to the growing intensity of the reaction. In leaves, the epidermal cells and the vascular tissues are just a little bit affected. How seer the mesophyll is completely disorganized, resulting in cell death. Injures are more obvious stems and leaves of $\mathbf{C}$. benghalensis. Morphologically, clorotic regions and deceased spots all over the leaf surface lead to leaf fall after $15^{\circ} \mathrm{DAA}$ in C. benghalensis. In C. diffusa, the leaf abscission is delayed, despite the injuries are almost the same. Both species presented higher quantities of starch in the node region than the internode. C. benghalensis has few and
\end{abstract}

Recebido para publicação em 30.10.2003 e na forma revisada em 5.3.2004.

2 Estudante de Mestrado em Fitotecnia, Dep. de Fitotecnia da Universidade Federal de Viçosa - UFV, 36570-000 Viçosa, MG; ${ }^{3}$ Professora do Dep. de Biologia Vegetal - UFV. ${ }^{4}$ Pesquisadora, EPAMIG, 36570-000 Viçosa-MG. ${ }^{5}$ Professor do Dep. de Fitotecnia - UFV. 
small starch grains, compared to many and big grains in C. diffusa. In response to glyphosate application, there was a variation in the number of starch grains in the stem to the time after the application. C. diffusa will always have larger possibilities to recover after glyphosate application because of its larger reservation of starch.

Key words: $\quad$ dayflowers, tolerance, chemical control.

\section{INTRODUÇÃO}

A flora daninha é muito diversificada, e no mercado existe grande número de herbicidas que têm potencial para controlar eficientemente a maioria delas. No entanto, seja pela utilização (dose/aplicação) incorreta, seja pela escolha inadequada do produto ou mesmo pelo uso ininterrupto do mesmo princípio ativo, algumas plantas daninhas têm tolerado a aplicação de herbicidas.

A tolerância de plantas daninhas a herbicidas pode ser atribuída ao estádio de desenvolvimento da planta, a diferenças na morfologia e anatomia foliar, diferenças na absorção, translocação, compartimentalização e ao metabolismo da molécula herbicida (Wyrill \& Burnside, 1976; Dall' Armellina \& Zimdahl, 1989; Tucker et al., 1994; Westwood et al., 1997; Vargas et al., 1999).

Em áreas onde o herbicida glyphosate tem sido utilizado com freqüência, a população de duas espécies do gênero Commelina, C. diffusa e $C$. benghalensis, popularmente conhecidas como trapoeraba, tem aumentado devido à tolerância às aplicações deste herbicida (Santos et al., 2001). Tanto C. diffusa quanto $C$. benghalensis apresentam grande eficiência reprodutiva, seja por sementes ou por partes vegetativas do caule, sendo capazes de sobreviver nos mais diversificados ambientes, dificultando o seu controle. Além disso, em C. benghalensis ocorrem flores cleistogâmicas subterrâneas, que produzem sementes viáveis, o que maximiza o problema do seu controle (Faden, 1992).

Santos et al. (2001b) observaram que tanto $C$. benghalensis quanto C. diffusa apresentaram danos severos após aplicação do glyphosate; contudo, plantas de C. diffusa mantiveram os caules vivos, o que possibilitou a rebrota desta espécie, sendo, assim, considerada mais tolerante ao glyphosate que C. benghalensis.

Em outro trabalho com as mesmas espécies, Santos et al. (2002) observaram que ambas apresentaram folhas anfiestomáticas, com número semelhante de estômatos e o mesmo tipo de pêlo secretor. Entretanto, apenas $C$. benghalensis apresentou pêlos tectores e maior número de pêlos em geral (secretores + tectores). O caule das duas espécies é um estelo do tipo atactostelo, sendo constatada a presença de amido de reserva. Enquanto em $C$. benghalensis os grãos de amido são pequenos e em número reduzido, em $C$. diffusa eles são grandes e numerosos.

Diante do observado, Santos et al. (2002) propuseram hipóteses para explicar a maior tolerância de C. diffusa. Algumas características da planta de $C$. benghalensis, como a presença de numerosos pêlos na epiderme adaxial, a produção de rizomas e de grande quantidade de sementes aéreas e subterrâneas (fortes drenos de fotoassimilados), poderiam favorecer a absorção e a translocação de herbicidas. Contrariamente, $C$. diffusa possui poucos pêlos na epiderme adaxial, maior capacidade de acumular amido nas células parenquimáticas do caule e não produz rizomas nem flores subterrâneas. Assim, esta espécie teria mais tempo que $C$. benghalensis para metabolizar o glyphosate antes de a reserva de amido se esgotar, permitindo a sua sobrevivência após a aplicação.

O presente trabalho teve como objetivos avaliar o efeito do glyphosate nas estruturas anatômicas e morfológicas do caule e das folhas de duas espécies de Commelina e investigar o envolvimento do amido de reserva na maior tolerância de $C$. diffusa ao glyphosate em relação a $C$. benghalensis. 


\section{MATERIAL E MÉTODOS}

O experimento foi conduzido de fevereiro a julho de 2002, em casa de vegetação, na Unidade de Crescimento de Plantas da Universidade Federal de Viçosa. Utilizou-se o delineamento inteiramente casualizado, com nove repetições e parcela experimental constituída de um vaso preenchido com três quilos de solo, onde foram plantadas cinco estacas de $15 \mathrm{~cm}$. As estacas foram retiradas de plantas matrizes, obtidas por multiplicação vegetativa de uma planta de $C$. diffusa e uma de C. benghalensis, ambas oriundas de semente. O pegamento das estacas foi de $100 \%$ nas duas espécies. A adubação de cobertura foi feita duas vezes com solução do adubo comercial OuroVerde $\left(3 \mathrm{~g} \mathrm{~L}^{-1}\right)$, sendo os vasos irrigados diariamente e capinados quando necessário.

Dos 10 vasos para cada espécie, um recebeu pulverização com apenas água e nove receberam o mesmo tratamento, que consistiu de $1.440 \mathrm{~g} \mathrm{ha}^{-1}$ eq.ac. de glyphosate na forma de sal de isopropilamina, aplicado como solução aquosa do produto comercial Roundup CS sobre as duas espécies de trapoeraba no início do florescimento. Utilizou-se pulverizador costal de precisão, propelido a gás carbônico, munido de barra com dois bicos do tipo leque TT110.03, operando a $300 \mathrm{kPa}$ de pressão e volume de calda correspondente a $200 \mathrm{~L} \mathrm{ha}^{-1}$.

Nos nove vasos, foram coletadas folhas do terceiro nó a partir do ápice caulinar e fragmentos de caule abrangendo o nó e o entrenó, entre a segunda e a quarta folha, antes da aplicação do glyphosate (tempo zero). Novas coletas foram feitas aos 15, 30 e 50 dias após a aplicação (DAA). A primeira coleta (tempo zero) foi considerada como testemunha. $O$ vaso que não recebeu herbicida também foi amostrado nas quatro épocas de avaliação, para comparação morfoanatômica entre plantas tratadas e não-tratadas. Durante esse período foram feitas observações visuais na morfologia das plantas.

Os materiais coletados foram imediatamente fixados em FAA $_{50}$, permanecendo por 24 horas dentro de frascos colocados em dessecador submetido a vácuo; posteriormente, foram estocados em álcool etílico $70 \%$. Amostras da porção mediana da folha foram incluídas e emblocadas em parafina, utilizando-se álcool butílico terciário para a desidratação (Johansen, 1940). Os blocos foram cortados transversalmente, em seqüência, em micrótomo rotativo de avanço automático com $10 \mu \mathrm{m}$ de espessura. Os cortes foram corados com safranina e azul-de-astra (Gerlach, 1984) e as lâminas montadas em bálsamo-do-canadá.

Cortes transversais da região do nó e entrenó foram obtidos em micrótomo de mesa, sendo posteriormente submetidos ao reagente lugol, para verificação da presença de amido; as lâminas foram montadas em glicerina + água 1:1 (Johansen, 1940). Após as preparações foram feitas avaliações visuais quantitativas da reserva de amido do caule. Atribuíram-se notas de 1 a 5 de acordo com a reação ao lugol, em que a nota 1 representa poucos grãos de amido e a nota 5, muitos grãos de amido (Figura 1).

Aos 36, 50 e 65 DAA foi verificada a eficácia do herbicida através de avaliação visual da porcentagem de controle em relação à testemunha, em que $0 \%$ corresponde à ausência de sintomas visíveis e $100 \%$ à morte das plantas (Frans, 1972).

\section{RESULTADOS E DISCUSSÃO}

Em resposta à aplicação de glyphosate, obteve-se melhor porcentagem de controle de C. benghalensis que de C. diffusa (Figura 2), o que confirma os resultados obtidos por Santos et al. (2001). Em C. benghalensis os sintomas de intoxicação foram mais evidentes tanto no caule quanto nas folhas. Nesta espécie observou-se senescência acentuada das folhas a partir dos 15 DAA do glyphosate, o que não foi verificado em $C$. diffusa, na qual a queda das folhas se mostrou mais eminente aos 30 DAA. Essa senescência começa nas folhas mais velhas e progride até o ápice caulinar.

Em C. benghalensis, as folhas foram eliminadas totalmente e seus ramos secaram pela ação do glyphosate, o que pode ser confirmado pela avaliação da porcentagem de controle, que chega a $98 \%$ nesta espécie aos 65 DAA controle este considerado excelente. Entretanto, C. diffusa manteve uma pequena porcentagem de folhas e os caules verdes, atingindo, aos $65 \mathrm{DAA}$, controle de apenas $62 \%$. Santos et al. (2001) observaram que tanto $C$. benghalensis quanto $C$. diffusa tiveram suas 

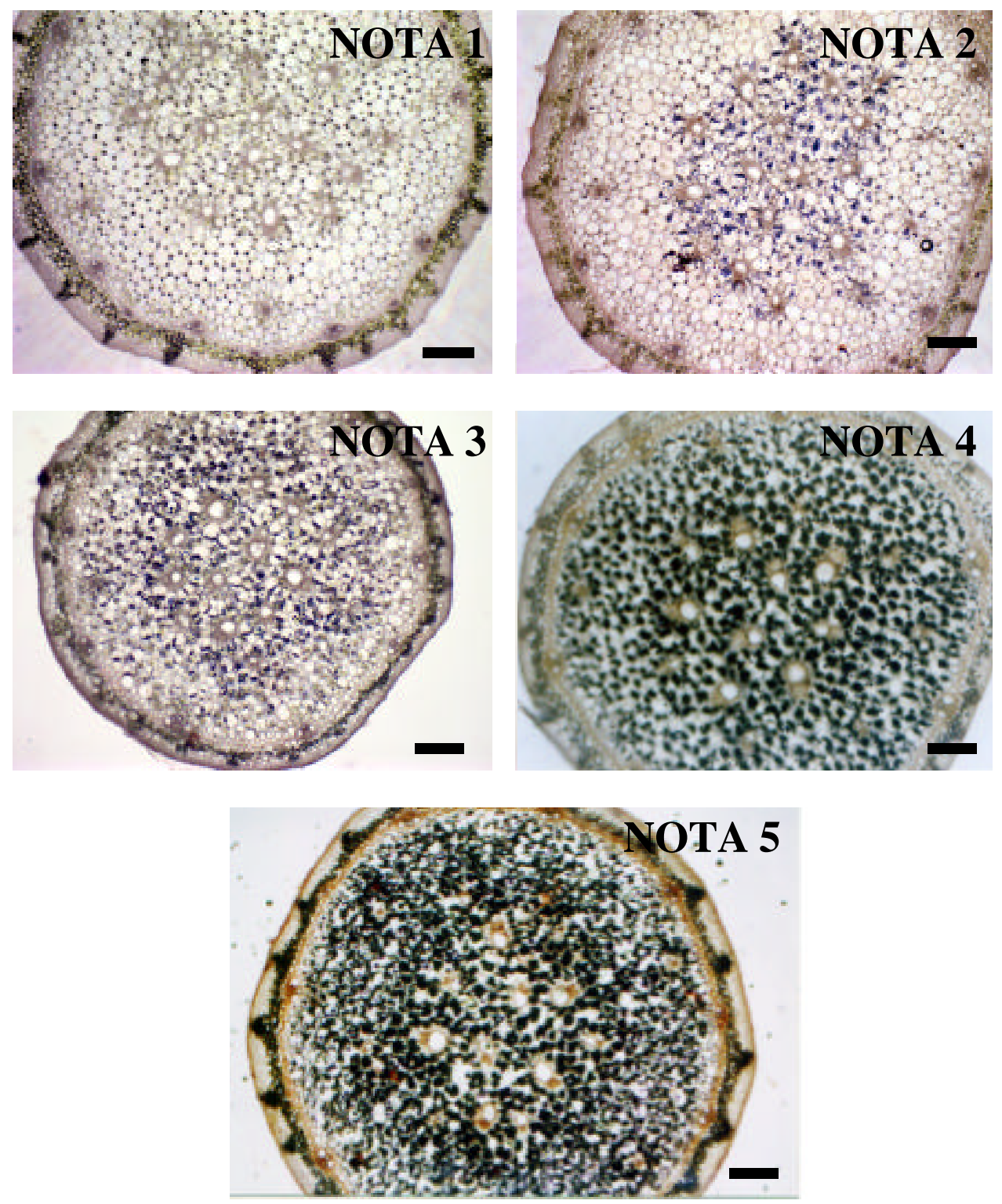

Figura 1 - Padrões utilizados na avaliação da quantidade de amido no caule. Barras de $20 \mu \mathrm{m}$.

folhas totalmente eliminadas pela ação do herbicida; contudo, somente C. diffusa, que manteve o caule vivo, emitiu novas brotações e se restabeleceu. Neste trabalho, a nãoemissão de brotações por C. diffusa, mesmo mantendo os caules vivos, pode estar ligada à severidade do tratamento e/ou à época de condução do experimento quando as condições climáticas eram desfavoráveis (inverno).

Nas folhas de ambas as espécies, as células epidérmicas e os tecidos vasculares foram pouco afetados, enquanto no mesofilo verificouse desorganização, principalmente pelo colapso dos espaços intercelulares do parênquima lacunoso. A desorganização do parênquima clorofiliano culminou com a morte das células, expressando-se morfologicamente como regiões cloróticas, que progrediram para áreas necrosadas, dispersas pela superfície. Essa mudança da coloração no tecido foliar pode estar relacionada à degeneração dos cloroplastos verificada por Campbell et al. (1976) em plantas tratadas com glyphosate. 


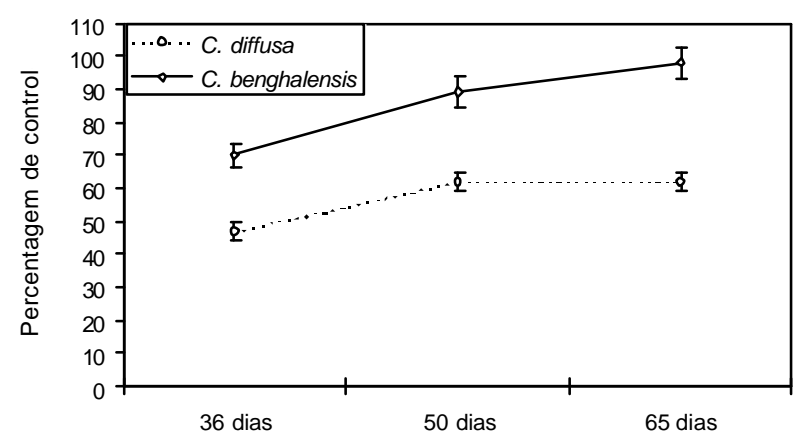

Figura 2 - Média da porcentagem de controle de duas espécies de Commelina, em função da aplicação de $1.440 \mathrm{~g} \mathrm{ha}^{-1} \mathrm{de}$ glyphosate. Média de nove repetições ( \pm desvio-padrão).

A quantidade de amido no caule variou entre espécies, entre local do corte (nó e entrenó) e entre épocas de coleta do caule ( $p<0,01)$; as interações, porém, foram não-significativas entre as fontes de variação ( $p>0,05)$.

C. diffusa apresentou maior concentração de amido no caule que $C$. benghalensis, confirmando resultados apresentados por Santos et al. (2002). C. benghalensis se reproduz por partes vegetativas do caule e, principalmente, por sementes aéreas e subterrâneas; em contrapartida, C. diffusa se reproduz basicamente por propagação vegetativa e produz poucas sementes. A maior concentração de amido no caule de $C$. diffusa pode ser vista como uma estratégia de reprodução, ou seja, como uma forma de manter nos seus caules energia, armazenada na forma de grãos de amido, para emissão de novas brotações e raízes.

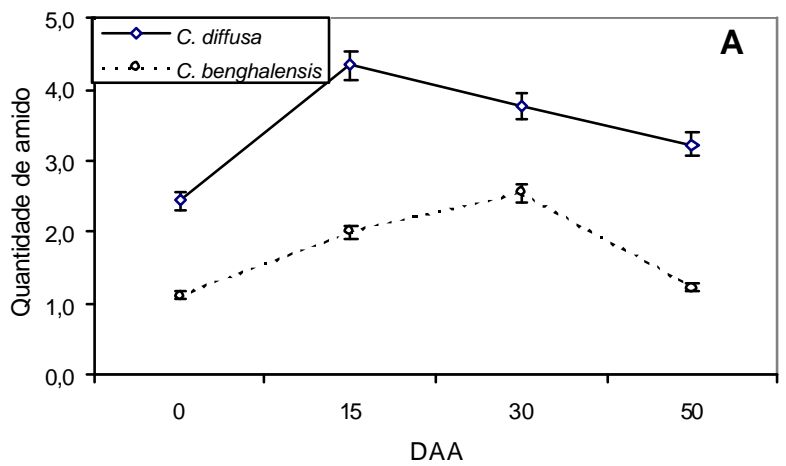

As duas espécies apresentaram, em geral, maior acúmulo de grãos de amido no nó que no entrenó do caule (Figura 3), tanto antes quanto após aplicação do glyphosate. $\mathrm{Na}$ avaliação realizada aos 15 DAA, a quantidade de amido no caule das duas espécies aumentou tanto no nó quanto no entrenó. Esse aumento se repetiu aos 30 DAA no nó das duas espécies e no entrenó de C. benghalensis. Aos 15 e 30 DAA ocorreu acúmulo do amido próximo aos feixes vasculares do caule das duas espécies. Em ambas, aos 50 DAA, a concentração de amido no nó e no entrenó foi menor que a observada aos 30 DAA, porém ainda maior que a da testemunha (0 DAA). Mesmo assim, ao final do tratamento, a quantidade de amido armazenada por $C$. difusa foi aproximadamente o dobro da quantidade armazenada por C. benghalensis (Figura 3).

C. benghalensis produz grande quantidade de flores aéreas e também flores subterrâneas, que são fortes drenos de fotoassimilados e, provavelmente, consomem a maior parte do amido produzido por esta espécie. Em contraste, C. diffusa emite poucas flores aéreas e não produz flores subterrâneas, possuindo, entretanto, maior volume de biomassa em relação a $C$. benghalensis, como ressaltado por Santos et al. (2001). Essas características, provavelmente, estejam ligadas ao fato de que C. diffusa produz e armazena maior quantidade de amido que $C$. benghalensis. A maior concentração de amido nos nós pode ser interpretada como uma elevada taxa de transporte de fotoassimilados para outras partes da planta, uma vez que nesta região ocorre uma concentração dos tecidos de condução.

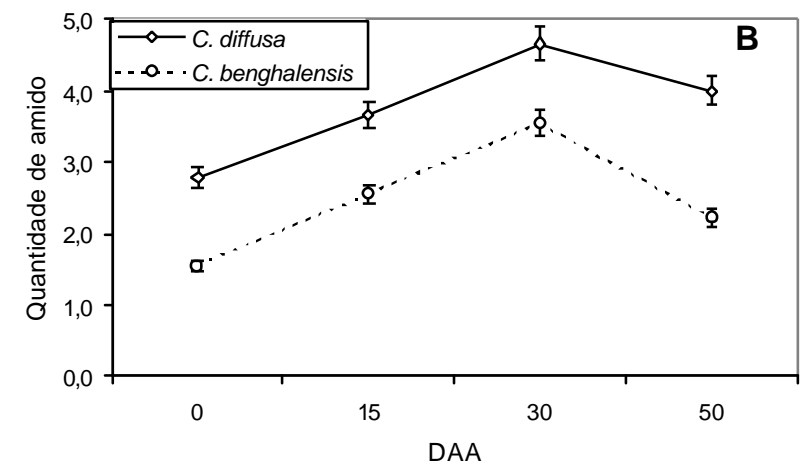

Figura 3 - Quantidade de amido no caule de C. benghalensis e C. diffusa antes e após aplicação de glyphosate (1.440 g ha-1). "A" corresponde à região do entrenó e "B" à região do nó do caule. Média de nove repetições ( \pm desvio-padrão).. 
Segundo Bromilow et al. (1990), o glyphosate é rapidamente translocado das folhas tratadas para os drenos metabólicos, principalmente para meristemas e órgãos de reserva. Seu sítio de atuação é a rota do ácido chiquímico, responsável pela produção dos aminoácidos aromáticos fenilalanina, tirosina e triptofano, que são indispensáveis para a síntese de proteínas e divisão celular (Cole et al., 1983; Foley et al., 1983; Hess, 1994). Assim, a diminuição do metabolismo nos drenos pela ação do glyphosate provavelmente permita que, a princípio, a planta acumule parte do amido antes requerido pelos drenos, uma vez que a senescência das folhas só é expressiva aos 15 DAA em C. benghalensis e aos 30 DAA em C. diffusa. Com a senescência das folhas, o amido usado pela planta para tentar sobreviver aos efeitos do glyphosate deixa de ser reposto, o que leva à diminuição de suas reservas.

Santos et al. (2002) sugerem que a maior quantidade de amido de reserva no caule de C. diffusa pode estar relacionada com a sua tolerância ao glyphosate. Esses resultados permitem supor que, mesmo que as duas espécies apresentem como resposta à aplicação do glyphosate o aumento e um posterior decréscimo na concentração de amido no caule, C. diffusa terá sempre maiores possibilidades de se restabelecer, por manter maior reserva de amido.

Considerando as condições de condução deste experimento, as seguintes conclusões foram possiveis: na folha, as células epidérmicas e os tecidos vasculares são pouco afetados - já o mesofilo é integralmente desorganizado, culminando com a morte celular; morfologicamente, verificam-se regiões cloróticas e áreas necrosadas dispersas pela superfície foliar, culminando com a abscisão a partir do 15을 DA em $C$. benghalensis, sendo mais tardia em C. diffusa; as injúrias são mais evidentes em C. benghalensis, apesar de serem semelhantes entre as espécies. Commelina diffusa possui maior quantidade de amido de reserva que C. benghalensis, mesmo após o tratamento com glyphosate; em ambas as espécies, a quantidade de amido no caule é maior na região dos nós, em relação aos entrenós; e, após o tratamento com o glyphosate, há aumento do amido de reserva do caule, seguido por decréscimo, que coincide com a senescência foliar.

\section{LITERATURA CITADA}

BROMILOW, R. H.; CHAMBERLAIN, K.; EVANS, A. A. Physicochemical aspects of phloem translocation of herbicide. Weed Sci., v. 38, p. 305-314, 1990.

CAMPBELL, W. F.; EVANS, J. O.; REED, F. C. Effect of glyphosate on chloroplast ultrastructure of quack grass mesophyll cell. Weed Sci., v. 24, p. 22-25, 1976.

COLE, D. J.; CASELEY, J. C.; DODGE, A. D. Influence of glyphosate on selected plant process. Weed Res., v. 23, p. 173-183, 1983.

DALL'ARMELLINA, A. A.; ZIMDAHL, R. L. Effect of watering frequency, drought, and glyphosate on growth of field bindweed (Convolvulus arvensis). Weed Sci., v. 37, p. 314-318, 1989.

FADEN, R. B. Proposal to conserve Commelina benghalensis (Commelinaceae) with a conserved type under art. 69.3 taxon, Utrecht, v. 41, p. 341-342, 1992.

FRANS, R. E. Measuring plant responses. In: WILKINSON, R. E. (Ed.) Research methods in weed science. (S.1.): Southern Weed Science Society, 1972. p. 28-41.

FOLEY, M. E. et al. Effect of glyphosate on protein and nucleic acid synthesis and ATP levels in common cocklebur (Xanthium pensylvanicum) root tissue. Weed Sci., v. 31, p. 76-80, 1983.

GERLACH, D. Botanische Mikrotechnik. Stuttgard: Georg Thieme Verlag, 1984. 311 p.

HESS, F. D. Mechanism of action of inhibitors of amino acid biosynthesis. In: Herbicide action: an intensive course on the activity, selectivity, behavior and fate of herbicides in plants and soil. West Lafayette: Purdue University, 1994. p. $344-365$.

JOHANSEN, D. A. Plant microtechnique. New York: Mcgraw-Hill Book, 1940. 523 p.

SANTOS, I. C. Biologia e controle químico de Commelina benghalensis L. e Commelina diffusa Burm. F. Viçosa: Universidade Federal de Viçosa, 2001. 81 p.

SANTOS, I. C. et al. Eficiência do herbicida glyphosate no controle de Commelina benghalensis e Commelina diffusa. Planta Daninha, v. 19, n. 1, p. 135-143, 2001.

SANTOS, I. C. et al. Caracteres anatômicos de duas espécies de trapoeraba e a eficiência do glyphosate. Planta Daninha, v. 20, n. 1, p. 1-8, 2002. 
TUCKER, T. A.; LANGELAND, K. A.; CORBIN, F. T. Absorption and translocation of ${ }^{14} \mathrm{C}$-imazapyr and ${ }^{14} \mathrm{C}$ glyphosate in alligatorweed Alternanthera philoxeroides. Weed Technol., v. 8, p. 32-36, 1994.

VARGAS, L. et al. Características da resistência de acordo com o mecanismo de ação do herbicida. In: VARGAS, L. et al. (Eds.) Resistência de plantas daninhas a herbicidas. Viçosa: Universidade Federal de Viçosa, 1999. 131 p.
WESTWOOD, J. H. et al. Absorption and translocation of glyphosate in tolerant and susceptible biotypes of field bindweed (Convolvulus arvensis). Weed Sci., v. 45, p. 658663, 1997.

WYRILL, J. B.; BURNSIDE, O. C. Absorption, translocation, and metabolism of 2,4-D and glyphosate in common milkweed and hemp dogbane. Weed Sci., v. 24, n. 6, p. 557-566, 1976. 